\title{
EMPOWERMENT OF PARENTS IN THE NEONATAL INTENSIVE CARE UNIT BY NEONA- TAL NURSES
}

\section{Adene Herbst}

B Cur (UP), M Cur (UP)

Registered nurse (general, psychiatric, community nursing), Midwife, Neonatal Nurse

\section{Carin Maree}

B Cur (UP), Diploma Paediatric Nursing, BA Cur (UNISA), M Cur (RAU), Diploma Neonatal Nursing (UP) Lecturer in Advanced Neonatal Nursing, Department of Nursing Science, University of Pretoria

Corresponding author: cmaree@postillion.up.ac.za

Keywords: empowerment; parents; neonatal intensive care nursing; neonatal nurses

\begin{abstract}
Parents of infants who are admitted to the neonatal intensive care unit (NICU) need to be empowered to improve bonding, attachment and care-giving skills. Neonatal nurses play a critical role in the empowerment of such parents, but often find it difficult due to a lack of clarity on how it has to be done. A qualitative contextual study, on which this article is reporting, was conducted to describe the parents' needs and suggestions for empowerment as obtained from parents. This was presented to purposive selected neonatal nurses during a workshop to derive guidelines for empowerment of parents in an NICU.
\end{abstract}

\section{OPSOMMING}

Ouers van babas wat in die neonatale intensiewesorgeenheid (NISE) opgeneem word, moet bemagtig word met die oog op bevordering van binding, 'n hegte band met die babas en versorgingsvaardighede. Neonatale verpleegkundiges speel ' $n$ kritiese rol in die bemagtiging van ouers, maar dit is vir verpleegkundiges dikwels baie moeilik, hoofsaaklik as gevolg van die gebrek aan duidelikheid oor hoe om dit te doen. 'n Kwalitatiewe kontekstuele studie, waaroor hierdie artikel verslag doen, is onderneem om ouers se behoeftes en voorstelle vir bemagtiging soos van ouers verkry, te beskryf. Dit is tydens ' $n$ werksessie aan doelbewus-geselekteerde neonatale verpleegkundiges voorgelê ten einde riglyne vir die bemagtiging van ouers in 'n NISE te bekom. 


\section{INTRODUCTION}

Newborn babies are admitted to the neonatal intensive care unit (NICU) if they need support to adjust from intra-uterine to extra-uterine life, or to maintain healthy bodily functions, whether they are preterm or full-term. They need to be admitted to a neonatal intensive care unit for specialised health care, provided by trained professionals with specialised knowledge and skills, utilising advanced medical technology. The parents are not able to provide such advanced care, and due to the risks involved, such as accidental extubation, parents are normally not allowed to provide basic care either (Verklan \& Walden, 2004:392-393).

The South African legal system has always regarded children as a vulnerable group in need of protection and certain rights. The South African Constitution therefore dictates, "Every child has the right to family care or parental care" (South Africa, 1996:13, Section 28(1)(a)), even during hospitalisation. Preterm and ill newborns are children in need of special protection, but up until now, little provision has been made for this particularly vulnerable group and their needs. Infants in the NICU have no legal capacity or ability to decide about their own treatment or even fate and are utterly reliant on adult representation for advocacy. Adult representation in this regard varies, as the decisions are made by various medical practitioners, nursing personnel and, in some cases even the hospital administration. Parents are usually excluded from the decision-making process in spite of the known importance of parental involvement (Kenner \& McGrath, 2004:18-19).

Information is available on the importance of parental involvement, parental needs and vulnerability in the NICU, as well as the consequences for parents and babies if the parents are not involved. Common outcomes of involved parents are psychosocial well-being, bonding with their child and responsible parenthood (Kenner \& McGrath, 2004:343-347; Verklan \& Walden, 2004:403-404). Uninvolvement commonly results in lack of bonding, neglect of children and higher risk of psychosocial illnesses such as maternal depression (Kenner \& McGrath, 2004:68).

The process to obtain parental involvement is referred to as 'empowerment'. Rodwell (1996:309) explains it as follows, "In a helping partnership it is a process of enabling people to choose to take control over and make decisions about their lives. It is also a process which values all those involved". Empowerment is crucial for parents in the NICU and nurses play a significant role in this regard (Kenner \& McGrath, 2004:343-357; Verklan \& Walden, 2004:392-409; Krebs, 1998:39; Bradley, 1996:722-727; Miles, Carlson \& Funk, 1996:51; Raines, 1996:7; Raines, 1993:47; Stewart, 1990:665), but limited information is available on how to empower parents regarding the NICU.

Verklan and Walden (2004:393) explain that neonatal nurses' primary concerns are the physiological and psychosocial needs of the patients, with the latter including bonding and therefore parental empowerment. Hickey (1990:401-415) states that, although nurses acknowledge their responsibility of caring for the parents of infants in the NICU, they admit that there is no common view on how to care for the parents or what the extent of care should be.

\section{PROBLEM STATEMENT}

Empowerment of parents in the NICU is crucial, but it is not clear how to transfer primary care-giving responsibilities to the parents. The aim of the reported study was therefore to explore and describe the empowerment of parents of infants in the NICU. The study was planned in two phases, of which the first phase was to describe empowerment of parents in the NICU according to parents' opinions on their needs for empowerment and suggestions on how to empower them. The second phase of the study was to compile practical guidelines on how to empower parents in the NICU by means of a workshop with neonatal nurses, based on the data obtained from the parents as well as the neonatal nurses' practical experience.

\section{RESEARCH QUESTION}

The focus of this study was, therefore, to explore and describe the empowerment of parents of infants in the NICU. Some questions had to be answered in this regard:

- What are the parents' needs with regard to empowerment?

- How can a parent in the NICU be empowered? 


\section{BACKGROUND AND LITERATURE REVIEW}

Empowerment of parents is influenced by their role in the NICU, needs of parents and the practical implications of empowerment for the neonatal professionals.

Under normal circumstances, changes take place when a healthy full-term baby is born into a family unit, creating excitement and eagerness in the family but also a lot of stress (Wilson, White, Cobb, Curry, Greene \& Popovich, 2000:205; Stewart, 1990:660). This stressful situation is aggravated when the baby, expected to be normal, has to be admitted to the NICU, or when the pregnancy has ended prematurely resulting in admission (Kenner \& McGrath, 2004:69).

Once the baby is admitted to the NICU, there is uncertainty about the parents' roles, what part they should play in the care of their child, and what claims they have on their child (Callery, 1997:997). The neonatal nurses commonly fulfil the role of the primary care-givers of the babies in the NICU (Kenner \& McGrath, 2004:342-246).

Factors significantly delaying to acceptance of the parental role pertain to the fact that parents of babies in the NICU do not have the reassurance of holding their baby, which usually brings about the realisation of parenthood (Stewart, 1990:660-664). Various additional stress factors are present, like the uncertainty around the baby's condition or even life-and-death uncertainty, and personal circumstances (Kenner \& McGrath, 2004:69).

Parents who are not assisted in developing their parental role may have trouble in assuming their responsibilities when the baby goes home (Stewart, 1990:660664). Complications might occur if parents are not involved in their child's care, such as problems with bonding and attachment, lack of parenting confidence, decreased maternal care-giving skills and reduced quality of the home environment (Loo, Espinosa, Tyler \& Howard, 2003: 31). Long-term consequences of a lack of parental involvement may include neglect, abuse and other parenting problems (Raines, 1996:8). Maroney (1994:133) comments, “... keeping parents naïve does not prevent lawsuits; it creates fear, suspicion and anger".
Cindy Rushton, neonatal/paediatric nurse practitioner and an authority in the field of ethics (quoted by Villaire, 1994:107-113) comments, "Some healthcare professionals make assumptions that because parents are emotionally involved with their children, experiencing shock and grief because of what's happened to their child, they are not the best persons to function as surrogates. I challenge that myth about parents. I am convinced that, although there are some barriers to the way in which they participate, generally parents are very capable of participating in a meaningful way in decisions".

The consequences of a disrupted family structure are so severe that nurses cannot afford to ignore them (Raines, 1996:8). If the parents could be empowered to become more involved in their child's care, they would not feel that the change in their role is such a major stressor and they would be more effective in parenting their child (Maroney, 1994:133). Parents have an overwhelming desire to be seen as partners in their child's care and want to retain some control - even in the NICU (Fisher, 2001:605).

The empowerment of the parents in the NICU is not without problems. Empowerment of parents in the NICU refers to the process of enabling the parents to make choices and decisions regarding the care of their babies, and therefore to gain partnership in their babies' care while in the NICU (Rodwell, 1996:309).

Nurses are crucial in facilitating this process in the NICU (Krebs, 1998:39; Bradley, 1996:722-727; Miles et al. 1996:51; Raines, 1996:7; Raines, 1993:47; Stewart, 1990, 665), but the nurses often find this empowering difficult. Few nurses have the skills or knowledge to deal with parents, let aside knowledge or skills to empower them (Tomlinson, Thomlinson, Penden-McAlpine \& Kirschbaum, 2002:161). Nurses have to spend time with the parents to empower them, which imply an increase in the workload of the nurses. Trends in neonatal care, such as the focus on case management and standardised protocols of care (Hegedus \& Madden, 1994:68); staff shortages and skill mix (Enslin, 2005:40) reduce the time available for nurses to spend time with the parents to empower them. This makes it even harder for the nurses. The parents often experience the NICU environment as threatening (Botha, 2005:40), which further complicates the process of empowerment. 
Empowerment of parents is usually implemented by individual nurses by reason of their own beliefs, and not as part of routine neonatal care. Implementation of empowerment of parents as routine neonatal care has its difficulties, like resistance to change (Kenner \& McGrath, 2004:344-345). Nurses regard parental demands for care as unpredictable and are of the opinion that there is a real need for learning to handle these demands. Research into this area would not only be helpful to parents but also to nurse practitioners (Callery, 1997:997).

Although empowerment of parents in the NICU are very important for the sake of the parents and their babies, the implementation thereof as routine neonatal care is not without difficulties. A significant related problem identified and being addressed in this reported study, states that there are no clear guidelines for nurses available on how to empower parents in the NICU. An assumption of the researcher is that there probably would be differences in the needs and the implementation of empowerment between NICUs in private and public health care sectors due to differences in the health care systems, socio-economic status of the clients, financial implications of admission and cost-awareness, as well as the higher risk for legal cases from the private sector.

The aim of the reported study was to describe guidelines for empowerment of parents in two particular NICUs in the private health care sector. The guidelines are based on the needs and suggestions of parents, and made relevant and applicable to the NICU by neonatal nurses.

\section{METHODOLOGY}

The study was done as a qualitative, contextual study, planned in two phases. The focus of the first phase was to obtain data from the parents' perspective, as they were the population to be empowered, and because these parents had experienced the NICU environment. The second phase was to obtain data from the neonatal nurses' perspective, as they would be responsible for the implementation of the process of empowerment of the parents in the NICU. Although these guidelines are needed in all NICUs, the study focused mainly on the private health care sector. Purposive sampling was used in both phases to obtain in-depth and rich data from participants who themselves were exposed to the particular context of the study (De Vos, Strydom, Fouché \& Delport, 2002:207, 335).

\section{Phase One: Description of parents' needs and suggestions for empowerment in the NICU}

The target population for the first phase was the parents of infants in NICUs in the private health care sector. Purposive sampling was done for focus groups with parents from two selected private hospitals in Gauteng where the researcher was involved at the time of the study (De Vos et al. 2002:207, 335; Polit \& Hungler, 1997:198).

Inclusion criteria for the selection of these parents were:

- they had to be parents of an infant who had been admitted to the NICU;

- they had to be able to communicate in English or Afrikaans; and

- they had to give informed consent to participate in the focus groups.

Criteria such as diagnosis, length of stay and gestational age were not specifically considered for the purpose of this study, as all parents need to be empowered.

\section{Data collection}

Two focus groups of ten to twelve parents were selected to collect data. The focus group interviews were advantageous because it enabled the researcher to obtain in-depth data on a human-related phenomenon. The participants were selected because of their common characteristics related to the topic (De Vos et al. 2002:305; De Vos, 1998:313-315; Polit \& Hungler, 1997:255). An experienced, independent interviewer conducted the focus groups to collect uncontaminated data, while the researcher was the field worker observing non-verbal communication and group dynamics. The participants were encouraged to self-disclosure to obtain multiple viewpoints that were needed (De Vos et al. 2002:306). Focus group interviews were audio taped.

The interviewer followed the below mentioned question guidelines during the focus groups, while complying with the prescribed focus group techniques according to De Vos et al. (2002:313-314): 
- How would you describe a parent that is empowered in NICU?

- Can you make some practical suggestions on how to empower parents?

Twelve participants (seven mothers and five fathers) attended the first focus group, and the ten participants that participated in the second focus group were five mothers and five fathers. All parents were staying in Pretoria, and were between the ages of 25 and 35 years.

The duration of both focus groups were close to one and a half hour each, scheduled a week apart. Both were held at the conference facilities of a private hospital in Pretoria.

\section{Data analysis}

The audio taped focus group interviews were transcribed verbatim, and analysed by means of qualitative content analysis through open coding in order to identify main themes and sub-themes. The process was repeated to ensure proper coding and to include the field notes taken during the interviews (Polit \& Hungler, 1997:378, 380-384). More focus groups would have been arranged, had data not been saturated.

\section{Phase Two: Description of neonatal nurses' suggestions of empowerment of parents in the NICU}

During the second phase, the needs and suggestions identified by the parents were presented during a workshop to a group of neonatal nurses who had the opportunity to make practical suggestions on how to empower the parents of infants in the NICU. Their input was based on the parents' needs and suggestions, as well as their own experience.

The target population was neonatal nurses in Gauteng. Using purposive sampling, thirty registered nurses from Gauteng were invited to attend a workshop to discuss possibilities on how to empower parents of infants in the NICU. Inclusion criteria for the selection of the nurses were:

- experience in neonatal intensive care for at least one year;

- ability to communicate in English or Afrikaans; and

- workshop attendance had to be voluntarily.
To ensure that the study participants contributed information-rich data, invitations were given to those registered nurses who were considered to be experts in neonatal intensive-care nursing, namely unit managers of NICUs, nurses enrolled for the Master's degree in Advanced Neonatal Nursing Science, or nurses who had already completed the above-mentioned degree.

\section{Data collection}

To collect data, a workshop was arranged for neonatal nurses, using the results of the previous phase. The results were presented to the nurses who then had the opportunity to debate solutions on how the parents' needs regarding empowerment could be met, taking into account the parents' suggestions and their own experiences in NICU. The researcher decided to have only one group due to time, cost and resource restraints. However, if data saturation had not been reached by the end of the data collection phase, additional workshops would be arranged. The data collected at the workshop was in-depth, rich data and it was deemed unnecessary for an additional workshop.

Twenty participants attended the workshop. The duration of the focus group was close to three hours. This focus group was held at the conference facilities of a private hospital in Pretoria.

\section{Data analysis}

A process similar to Phase One for qualitative content analysis was followed to identify and describe the main themes and sub-themes (Polit \& Hungler, 1997:379384).

\section{TRUSTWORTHINESS}

Methods put in place to enhance credibility, or the manner to ensure that the subject was accurately identified and described, included prolonged engagement of the researcher in the field, in-depth description of the research process, and triangulation of sources (different groups of participants and literature) (Polit \& Hungler, 1997:305; De Vos et al. 2002:351-352; Krefting, 1991:214-222).

Transferability, or the application of the findings to another setting or context, was not the main aim of the study, as it was a contextual study. The main method to enhance transferability though was in-depth descrip- 
tion of the research process (Polit \& Hungler, 1997:305; De Vos et al. 2002:352; Krefting, 1991:214-222).

Dependability, or reliability of the study was strengthened by the methods to enhance credibility, as well as the use of an independent chairperson for the focus groups, and an independent co-coder (Polit \& Hungler, 1997:305; De Vos et al. 2002:352; Krefting, 1991:214222).

Confirmability or objectivity of the study was mainly increased by thick description of the research process (Polit \& Hungler, 1997:305; De Vos et al. 2002:352; Krefting, 1991:214-222).

\section{ETHICAL CONSIDERATIONS}

Institutional consent was obtained from the two private hospitals involved and ethical approval was granted by the Ethics Committee of the Faculty of Health Sciences, University of Pretoria. Informed consent was obtained from the relevant parents and neonatal nurses.

Throughout the study, participant confidentiality and anonymity were upheld (Polit \& Hungler, 1997:137-138). The study was based on the principles of beneficence. The study participants were not subjected to any exploitation since they were not expected to expose themselves and the information they provided would in no circumstance be used against them.

\section{RESULTS AND FINDINGS}

The neonatal nurses decided on practical guidelines on how to empower parents in an NICU, based on the needs and suggestions of the participants (parents) of the focus groups, and their own experiences of the realities of an NICU. The term 'participants' in the discussion below refers to the parents of babies in the NICU who participated in the focus group interviews.

\section{Prior preparedness of parents}

Several participants verbalised their need for preparation on what they could expect, even before their child was admitted to the NICU, as "... coming into the ICU department, to me I felt very out of place".

Guideline: Parents should be provided with informa- tion before admission to the NICU, even though most of the infants would not need specialised care. It has to be a combined responsibility of the multi-disciplinary team members involved in the mother or infant's care and can be done at antenatal classes, on a guided tour, or as written information.

\section{Orientation of parents on admission to the NICU}

The participants wanted to receive the same information on orientation regardless of whether their child was critically ill or simply admitted for observation, covering aspects such as visitation and what they can expect.

They also wanted to be introduced to the person/s looking after their child, as one parent stated, " ... one of the good things that we have encountered in this hospital is that we pretty much get introduced to the person that is looking after our kids. And that immediately puts me at ease ...".

Guideline: Each unit should have an orientation programme for parents, clarifying their roles and what they can expect. An experienced neonatal nurse should do orientation on a one-to-one basis as soon as possible after admission. Orientation can be supplemented in the form of a pamphlet or booklet to enhance consistency. Parents should be introduced to the NICU staff responsible for their child's care.

\section{Informed decision-making}

It was very important for the participants to be informed about everything that could possibly be relevant to their child's condition - causes, progress, outcomes, treatment, their infants' behaviour, and all that happened while they were not present. Participants who had been kept informed appreciated it, while the ones from whom information was withheld described it as "extremely stressful'.

Participants agreed that neonatal nurses should have good judgement to decide what amount of information a parent would be able to cope with at a particular time. The participants identified inconsistency and incompleteness of information as being problematic.

It was crucial for all participants to be involved in deci- 
sion-making regarding their child's care. They felt it was their right to be informed about the possible choices, in order to get an opportunity to ask questions and be answered adequately, and to be acknowledged as a significant influence in the decision-making process, especially where it concerned a serious matter, and they wanted access to their children's medical records as part of being informed.

Participants suggested a centre where they could find additional information about infants in the NICU, specific conditions, support groups and more.

Guidelines: Parents should be informed about everything that concerned their child: condition, investigations, outcomes, motivation for treatment and care, progress or setbacks, or any other relevant detail. Information in the medical records should be discussed with them to interpret it in context, and access to it should not be denied.

Parents should be involved in the decision-making process - they should be informed of the available options, get an opportunity to ask questions and be satisfied with the answers, and be allowed to give input. The decisions regarding their child's care ought to be discussed until all parties involved are satisfied.

Additional information should be available, such as pamphlets, magazines, books, relevant research reports and the Internet. Parents should be motivated to discuss the information they find with the neonatal staff in order to prevent misinterpretation and wrong conclusions.

\section{Participation of the parents in basic care of their baby}

The participants wanted to participate in their children's care, "to hold them and care for them", and "to do what parents are supposed to do for their children".

Guidelines: Parents should be encouraged to participate in their children's care, but their roles should be clear. They have to be informed about the principles of developmental care and how they can implement it, and how to change nappies or assist with feeding, while preventing potential risks such as accidental extubation or disconnection of intravenous lines. They should especially be encouraged to visit as often as possible, to make skin-to-skin contact and to talk softly to their baby. They could be encouraged to personalise their baby's immediate environment. Parents should be discouraged to perform nursing or medical interventions such as suctioning, drug administration and adjustments of ventilator settings.

The grandparents, siblings, children and friends supporting the infant's parents should be briefed on their role during hospitalisation. Siblings and other important family members should, where possible, be involved in the infant's care as agreed with the parents.

\section{Emotions experienced by parents in the NICU}

The participants experienced many different and very intense emotions and often did not know how to deal with them. Some described denial, "You do not think that it can happen to you." Some experienced guilt, as one participant verbalised, "You feel like a failure. I mean, this is the one thing in your life that is supposed to be normal and it is the one thing that I cannot get right ... you feel like a failure". Other feelings described, were helplessness, dependency, vulnerability and being overwhelmed. Anger, frustration, fear and anxiety were common feelings identified, "I mean, I am always in control and I always know what to do. I don't have patience. And here you are!' Several experienced feelings of separation and isolation, "... nobody knows what you are going through. ... And you feel alone. You really do".

Guidelines: Parents' emotions should be accommodated during the hospitalisation of their children. Neonatal staff should be aware of the emotional turmoil experienced by parents even if parents do not show emotions, and parents should be treated with empathy.

Neonatal staff should be sensitive about parents' emotional coping abilities and should take these into consideration when giving them information. Parents should be treated according to their individual needs, which is only possible if the staff get to know the parents and a non-threatening, trusting relationship is established. 


\section{Communication and building trusting relationships}

The participants felt that communication was crucial if parents were to be empowered. First impressions are important, but lasting impressions are even more important. Confidentiality and trusting relationships were identified as crucial, as well as professionalism and competency. Parents expect honest and open communication regarding all aspects relevant to their children, but at the same time sensitivity, as regards the transfer of information. Parents appreciate attempts to answer all their questions in an understandable manner, and even repetition should they forget or not be in a receptive emotional state.

The parents preferred informal communication on a firstname basis. They wanted the same staff to care for their children, instead of a rotation system. Freedom to call the NICU at any time and encouragement to ask questions were highly valued, while the lack of communication with their children's paediatricians was identified as a limitation to their own empowerment. These made the parents feel insecure. They expressed a need for reassurance and positive feedback when, for example, they were holding their child.

Guidelines: For positive first impressions, staff members should be friendly, caring, approachable and knowledgeable when preparing for hospitalisation and orientating parents before or on their child's admission to the NICU. Communication should be a continuous process achieved by listening properly, encouraging, questioning and providing parents with complete, thorough, consistent and honest information. Neonatal staff should be empathetic, supportive and realistic, using clear language at a level appropriate to the parents. If the parents speak a foreign language, where possible an interpreter should be arranged to ensure meaningful communication.

Parents should be complimented on the way they contribute in the NICU and encouraged to participate in the care of their children. The nurse should be the mother's eyes and ears if the mother is unable visit her baby, the nurse should tell the mother everything - from her baby's condition, to what her baby looks like. A footprint of her baby's foot and pictures of the baby could be shown to the mother and she should at all times be reassured that she is not to be blamed for the fact that her baby is in the NICU.

It would be unrealistic to expect the neonatal nurses to change the paediatricians' and other team members' relationship with parents. Nurses could however enhance communication between the various parties involved by maintaining good relationships and communication with the other team members and, for example facilitate or suggest the making of appointments.

\section{A therapeutic NICU environment and privacy}

The participants described the NICU environment as "demoralising", "depressing" and "threatening", with a lack of privacy. The parents made suggestions on how the environment could be changed to make the stay for the parents and their babies more positive, for example by:

- decreasing the noise levels in the NICU (answering alarms as soon as possible and talking softly);

- $\quad$ trying to provide the parents with enough space;

- providing comfortable seating facilities;

- providing breastfeeding facilities where the father could also be present without disturbing other mothers;

- painting the walls any colour other than white;

- providing young children who were visiting the unit with something to entertain themselves outside the NICU; and

- by having a window through which visitors could view the babies.

Guidelines: The NICU should be a therapeutic milieu for the babies through implementation of developmental care. The neonatal staff should be innovative to make the environment as comfortable and private as possible for the parents. It is recommended that the environment be discussed with parents for their opinion and input, and to provide them with information. Parents should be allowed some private time with their children, even if it is a critically ill infant. A therapeutic environment for the parents should never compromise the safety of their infants or the quality care given to the babies. 


\section{Preparation for discharge}

The participating parents verbalised that they were scared of the period after discharge and that they needed preparation for questions such as, "What do I do when I take this child home? It is a prem?' One parent called it "NICU-withdrawal symptoms". Having someone whom they could contact with questions and problems was very important to them.

Guideline: Parents should be prepared before discharge from the NICU to take care of their child from admission. They should be involved in pre-discharge planning for their child in terms of criteria for discharge, health education needs of parents, post-discharge follow-up, specific support or additional therapy applicable, contact numbers and information sources.

\section{Perceived quality of nursing care}

The participants identified the perceived quality of nursing care as playing a significant role in their own empowerment. Quality of nursing care for them implied knowledgeable staff, a caring and supportive attitude, consistency and individualised care. They felt that quality of care would reduce their fears and stress, and would enhance communication, trusting relationships and their own empowerment.

Guidelines: High quality nursing care of the babies should remain the highest priority, and the parents' perception thereof should be enhanced by means of all the abovementioned guidelines.

\section{Optimal unit management}

The participants did not identify the relevance of optimal unit management, but the neonatal nurses concluded that it was a basic prerequisite for empowerment of parents in the NICU.

Guidelines: Aspects of importance for successful empowerment of parents in the NICU include the underlying philosophy, vision and mission of the hospital and an NICU supportive of a family-centred approach, the unit manager's style of management, and training and development of the neonatal staff on the relevance of empowerment and skills to empower parents.
Additional factors included sufficient staff members per shift to provide quality nursing care and to have time for the parents, encouragement to empower parents and rewards for positive feedback from the parents during or after their child's stay in the NICU.

\section{DISCUSSION}

Parents experience intense stress if their newborn is in need of neonatal intensive care, which is associated with feelings of anxiety, disappointment and grief. The admission to the NICU and the stress-provoking circumstances cause disruptions in the bonding process between the parents and their child. This in turn has a long-term impact on the child's sense of self and all future relationships. The facilitation of parent-infant interaction and attachment therefore has to be an important component of the nursing care of NICU patients (Verklan \& Walden, 2004:403). If the parents had not been given an opportunity to be responsible and involved with their child's care, this transition from hospital to home could be difficult and long-term negative outcomes are possible (Loo et al. 2003:31; Stewart, 1990:664).

Parent-infant bonding can be facilitated through the process of empowerment of the parents, during which the parents are informed about and involved as partners in their babies' care and decision-making (Botha, 2005:43; Rodwell, 1996:309). Interaction with their babies will thus be facilitated and parents will be supported in their parental role, which both contribute to the bonding process (De Kock \& Van der Walt, 2004:29, 36-29, 38; Verklan \& Walden, 2004:403-407).

It is difficult to implement the process of empowerment in an NICU. The process needs compromise and openmindedness by the neonatal staff to involve parents, as such involvement has to do with interpersonal relationships and human characteristics such as emotions and perceptions (Sully \& Dallas, 2005:152-172). Practical guidelines, such as the ones described in this article, could assist in making this difficult process a reality in the NICU.

An underlying assumption of the guidelines is that the audience is familiar with the principles of developmental care, communication skills and the creation of a therapeutic environment. 


\section{LIMITATIONS OF THIS STUDY}

\section{The use of focus groups}

The use of focus groups unfortunately had some disadvantages. Bias and subjectivity might have influenced the quality of the data. The researcher has already discussed how this was prevented in the measures to ensure trustworthiness. Using a competent interviewer also decreased these disadvantages significantly.

\section{Transferability}

Since only two private hospitals were used in the study, the transferability of the results of this study might possibly be limited to only NICU's in private hospitals in Gauteng. However, as these results are supported by the literature review done by the researcher, it could be assumed that parent's of infants in NICU's of other hospitals experience similar needs.

\section{CONCLUSIONS AND RECOMMEN- DATIONS}

Empowerment of parents of babies admitted to the NICU is of critical importance for the infant-parent bonding and mental health well-being of the parents and the infants alike (Verklan \& Walden, 2004:403). The practical implementation of empowerment of parents in an NICU by the neonatal nurses is often complicated by several factors such as a lack of knowledge and the skills on how to do it, lack of time due to staff shortages and a negative attitude of neonatal staff regarding a family-centred approach (Kenner \& McGrath, 2004:343-347).

An important reason given by nurses for the lack of parental empowerment in the NICU was the lack of clear guidelines on how to empower parents, and this led to the reported qualitative descriptive contextual study. The main aim of the study on which this article is based, was the description of practical guidelines on how to empower parents in the NICU, which was planned in two phases. The focus of the first phase was the description of the needs for empowerment and suggestions on how to empower parents in the NICU, as obtained by means of focus groups involving parents whose infants had been admitted to two private sector NICUs. The results were verified by an independent coder and were presented to a group of neonatal nurses during a workshop. The neonatal nurses gave input for practical guidelines based on these results, as well as their own experiences of the reality of neonatal intensive care nursing.

Practical guidelines compiled to empower parents in the NICU, focused on:

- preparation of parents prior to admission of their babies to the NICU;

- orientation of the parents on admission or as soon as possible thereafter;

- informed decision-making by the parents;

- participation of parents in the basic care of their babies;

- emotions experienced by parents;

- communication and the building of trusting relationships;

- creating a therapeutic environment and privacy;

- preparation for discharge;

- parents' perception of the quality of nursing care; and

- the relevance of optimal management of the NICU.

These practical guidelines are derived from the private health care sector, but they are versatile enough to be applied in all NICUs to empower parents. The guidelines are generic and can be refined to particular NICU contexts for inclusion in unit policies.

Follow-up research on the impact and efficacy of empowerment of parents in the NICU once the guidelines have been implemented in practice is recommended. Suggestions for follow-up research include the parents' experience of such empowerment, the impact on parent-infant bonding and the post-discharge period. The guidelines could also be adjusted to other nursing disciplines, for example, paediatric nursing.

Empowered parents would not only be more involved and take responsibility for their child's care but should also be satisfied health care consumers. Each hospitalised infant has the legal and moral right to have empowered parents, and it is the obligation of all neonatal nurses to ensure this right is achieved in the NICU.

\section{REFERENCES}

BOTHA, KFH 2005: Om ouers van 'n premature baba in 'n neonatale 
intensiewesorgeenheid te wees - 'n selfreflekterende gevallestudie. Health SA Gesondheid, 10(3):36-45.

BRADLEY, SF 1996: Processes in the creation and diffusion of nursing knowledge: An examination of the developing concept of family-centered care. Journal of Advanced Nursing, 23(4):722727.

CALLLERY, P 1997: Caring for parents of hospitalized children: A hidden area of nursing work. Journal for Advanced Nursing, 26(5):992-998.

DE KOCK, J \& VAN DER WALT, C 2004: Maternal and newborn care: A complete guide for midwives and other health professionals. Paarl: Juta.

DE VOS, AS (ed) 1998: Research at grass roots: A primer for the caring professions. Pretoria: JL van Schaik.

DE VOS, AS; STRYDOM, H; FOUCHÉ, CB \& DELPORT, CSL 2002: Research at grass roots for the social sciences and human service professions; $2^{\text {nd }}$ edition. Pretoria: Van Schaik.

ENSLIN, P 2005: Taking the plight of the nurses to the public campaign. Nursing Update, March 2005:40.

FISHER, HR 2001: The needs of parents with chronically sick children: A literature review. Journal of Advanced Nursing, 36(4):600-607.

HEGEDUS, KS \& MADDEN, JE 1994: Caring in a neonatal intensive care unit: Perspectives of providers and consumers. Journal of Perinatology and Neonatology, 8(2):67-75.

HICKEY, M 1990: Family needs in critical care. Heart and Lung: The Journal of Acute and Critical Care, 19(4):401-415. KENNER, C \& McGRATH, JM 2004: Developmental care of newborns and infants: A guide for health professionals. St Louis: Elsevier.

KREBS, TL 1998: Clinical pathway for enhanced parent and preterm infant interaction through parent education. Journal of Perinatal and Neonatal Nursing, 12(2):38-49.

KREFTING, L 1991: Rigor in qualitative research: The assessment of trustworthiness. American Journal of Occupational Therapy, 45(3):214-222.

LOO, KK; ESPINOSA, M; TYLER, R \& HOWARD, J 2003: Using knowledge to cope with stress in the NICU: How parents integrate learning to read the physiologic and behavioral cues of the infant. Neonatal Network, 22(1):31-37.

MARONEY, D 1994: Helping parents survive the emotional "Roller Coaster Ride" in the newborn intensive care unit. Journal of Perinatology, 14(2):131-133.

MILES, MS; CARLSON, J \& FUNK, SG 1996: Sources of support reported by mothers and fathers of infants hospitalized in a neonatal intensive care unit. Neonatal Network, 15(3):45-52.

POLIT, DF \& HUNGLER, BP 1997: Essentials of nursing research Methods, appraisals and utilization; $4^{\text {th }}$ edition. New York: Lippincott-Raven.
RAINES, D 1993: Deciding what to do when the patient can't speak: A preliminary analysis of an ethnographic study of professional nurses in the neonatal intensive care unit. Neonatal Network, 12(6):43-48.

RAINES, DA 1996: Parents' values: A missing link in the neonatal intensive care equation. Neonatal Network, 15(3):7-12.

RODWELL, CR 1996: An analysis of the concept of empowerment. Journal of Advanced Nursing, 23:305-313.

SOUTH AFRICA 1996: The constitution of the Republic of South Africa Act 108 of 1996. Pretoria: Government Printing.

STEWART, AJ 1990: Mums and dads need care too - Supporting parents of babies in neonatal units. Professional Nurse, 5(12):660-665.

SULLY, P \& DALLAS, J 2005: Essential communication skills for nursing. London: Elsevier/Mosby.

TOMLINSON, PS; THOMLINSON, E; PENDEN-MCALPINE, C \& KIRSCHBAUM, M 2002: Clinical innovation for promoting family care in paediatric intensive care: demonstration, role modelling and reflective practice. Journal for Advanced Nursing, 38(2):161-170.

VERKLAN, MT \& WALDEN, M 2004: Core curriculum for neonatal intensive care nursing; $3^{\text {rd }}$ edition. Philadelphia: Elsevier.

VILLAIRE, M 1994: Interview: Cindy Rushton. Critical Care Nursing, $14(2): 106-113$.

WILSON, ME; WHITE, MA; COBB, B; CURRY, R; GREENE, D \& POPOVICH, D 2000: Family dynamics, parental-fetal attachment and infant temperament. Journal of Advanced Nursing, 31(1):204-210. 